\title{
ACE inhibitors reduced cardiovascular events and all cause mortality in elderly people with hypertension
}

Wing LM, Reid CM, Ryan P, et al. A comparison of outcomes with angiotensin-converting-enzyme inhibitors and diuretics for hypertension in the elderly. N Engl J Med 2003;348:583-92.

\section{QUESTION: In older people with hypertension, is a regimen based on angiotensin converting enzyme (ACE) inhibitors more effective than one based on diuretics for reducing cardiovascular events and all cause mortality?}

\section{Design}

Randomised (allocation concealed*), blinded (outcome assessors),* controlled trial with median follow up of 4.1 years (Second Australian National Blood Pressure Study [ANBP2]).

\section{Setting \\ 1594 family medical practices in Australia.}

\section{Patients}

6083 patients who were 65-84 years of age (mean age 72 y, $51 \%$ women) without recent (previous $6 \mathrm{mo}$ ) cardiovascular events and had hypertension (defined as systolic blood pressure $\geq 160 \mathrm{~mm} \mathrm{Hg}$ or diastolic blood pressure $\geq 90 \mathrm{~mm} \mathrm{Hg}$ with systolic blood pressure $\geq 140 \mathrm{~mm} \mathrm{Hg}$ ). Exclusion criteria included any life threatening illness, a plasma creatinine concentration $>221 \mu \mathrm{mol} / \mathrm{l}$, malignant hypertension, and dementia. Follow up was $100 \%$.

\section{Intervention}

Patients were allocated to a treatment regimen based on ACE inhibitors $(n=3044)$ or diuretics $(n=3039)$ as the initial recommended therapeutic agents. However, the choice of the specific agent and dose was made by the family practitioners.

Sources of funding: Australian

Commonwealth

Department of Health and Aging; National Health and Medical Research Council of Australia; Merck Sharp $\mathcal{E}$ Dohme, Australia.

For correspondence: Dr C M Reid, Baker Heart Research Institute, Melbourne, Victoria, Australia. chris.reid@baker.edu.au

Abstract and commentary also appear in $A C P$ Journal Club.

\section{Main outcome measures}

The primary outcome was a composite of all cardiovascular events and all cause mortality.

\section{Main results}

Analysis was by intention to treat. At the end of the study, $58 \%$ of patients randomly assigned to the ACE inhibitor group and $62 \%$ of those assigned to the diuretics group were still receiving the assigned treatment. At 5 years, blood pressure had decreased by $26 / 12 \mathrm{~mm} \mathrm{Hg}$ from baseline in both groups. The rate of the composite outcome was lower in patients who were allocated to the ACE inhibitor group than in those who were allocated to the diuretics group $(\mathrm{p}=0.05)$ (table).

Angiotensin converting enzyme (ACE) inhibitors $v$ diuretics in older persons with hypertension at 5 yearst

\begin{tabular}{rllll} 
& \multicolumn{2}{c}{ Rate per 1000 patient years } & & \\
\cline { 2 - 3 } Outcome & ACE inhibitors & Diuretics & Hazard ratio $(95 \% \mathrm{Cl})$ & NNT (CI)‡ \\
$\begin{array}{rllll}\text { Composite } \\
\text { outcome }\end{array}$ & 56.1 & 59.8 & $0.89(0.79$ to 1.00$)$ & $32(18$ to 445$)$ \\
\hline
\end{tabular}

†Composite outcome $=$ all cardiovascular events and all cause mortality. Abbreviations defined in glossary; NNT and $\mathrm{Cl}$ provided by author.

$\ddagger$ Number needed to treat with an ACE inhibitor based regimen for 5 years to prevent 1 additional first cardiovascular event or death within the first 5 years after treatment began.

\section{Conclusion}

In older people with hypertension, a treatment regimen based on angiotensin converting enzyme inhibitors was more effective than one based on diuretics for reducing a composite outcome of all cardiovascular events and all cause mortality.

*See glossary.

\section{COMMENTARY}

The Antihypertensive and Lipid Lowering Treatment to Prevent Heart Attack Trial (ALLHAT) ${ }^{1}$ is considered by some to be one of the most important hypertension studies of all time. This large and well designed study showed that essentially no differences existed in outcomes among patients randomised to regimens initiated with the use of ACE inhibitors, calcium channel blockers, and diuretics. However, ANBP2, published a few months later, found that ACE inhibitors provided an "outcome advantage" over a diuretic based regimen, leading one renowned hypertension expert to bemoan "What are we to believe?"

Some definite differences exist between the studies. Less than $50 \%$ of the ALLHAT population was white, compared with $95 \%$ of the ANBP2 population. If ACE inhibitors have more positive effects on whites than on non-whites, independent of blood pressure lowering effects, this could affect the results. Baseline risks also differed. Both of these studies were very large, and very large studies tend to find statistically significant differences between treatments that actually have very little clinical difference. In the study by Wing $e t a l$, the difference in the rate of events was small (ie, 3.7 events per 1000 patient years), the rate of abandoning allocated therapy was large (about $40 \%$ in each group), and the upper limit of the number needed to treat was $>400$ patients. Thus, the difference is not very clinically important, despite the statistical significance.

The emphasis on relatively minor improvement in outcomes by diuretics in ALLHAT and by ACE inhibitors in the current study tends to obscure the most important result: that there are essentially no clinically important differences between these therapies, and that in uncomplicated patients, diuretics as a first line choice are likely to provide an excellent (and unsurpassed) outcome. Given the poor awareness and management of hypertension," our efforts would best be used to improve the latter as opposed to the tedious arguments about the superiority of one drug over another.

Richard Davidson, MD, MPH University of Florida College of Medicine Gainesville, Florida, USA

1 Major outcomes in high-risk hypertensive patients randomized to angiotensin-converting enzyme inhibitor or calcium channel blocker vs diuretic: The Antihypertensive and Lipid-Lowering Treatment to Prevent Heart Attack Trial
(ALLHAT).JAMA 2002;288:2981-97.

Frohlich ED. Treating hypertension-what are we to believe? [editorial]. N Engl J Med 2003;348:639-41. Moser M. No surprises in blood pressure awareness study
findings: we can do a better job [editorial]. Arch Intern Med 2003;163:654-6. 